\title{
Simulações de Experiências como Ferramenta de Demonstração Virtual em Aulas de Teoria de Física
}

\author{
Simulations of experiments as a virtual demonstration tool in physics lectures \\ Issao Yamamoto e Vagner Bernal Barbeta \\ Departamento de Física, FEI, Faculdade de Engenharia Industrial \\ Fundação de Ciências Aplicadas \\ Av. Humberto de A. C. Branco, 3972 \\ 09850-901, S. B. Campo, S.P. \\ e-mail: issaoyam@cci.fei.br
}

Recebido em 06/12/2000. Aceito em 30/05/2001

\begin{abstract}
As possibilidades do uso do computador como ferramenta pedagógica já vêm sendo discutidas há algum tempo. Entre estas possibilidades, a simulação de experiências de Física é a que tem sido mais explorada. As simulações permitem o estudo de condições que na prática seriam difíceis e, às vezes, até mesmo inviáveis de serem realizadas em um laboratório didático. A utilização de programas de simulação possibilita ainda uma melhor compreensão de certos fenômenos físicos na medida em que torna possível a inclusão de elementos gráficos e de animação em um mesmo ambiente. Isto, aliado ao interesse dos estudantes pelo microcomputador, pode a princípio tornar mais eficiente e agradável o processo de aprendizagem. Neste trabalho são apresentadas algumas simulações que vêm sendo aplicadas no ensino de Física, com alunos dos períodos iniciais do curso de Engenharia da Faculdade de Engenharia Industrial (FEI). Estas simulações têm sido criadas através do uso de um software comercial e são utilizadas em aulas de teoria como ferramenta de demonstração.
\end{abstract}

The possibilities of using computers as a pedagogical tool have been discussed for some time. Among these possibilities, simulation of physics experiments has been the most explored one. Simulation of physics experiments has allowed the study of conditions that would be difficult to be implemented in practice or, sometimes, not possible to be obtained at all. The use of simulation programs allows a better understanding of some physical phenomena since it makes possible to include graphical elements and animations in the same environment. This, allied to the interest of students in microcomputers, could make the learning process more efficient and enjoyable. In this work we present some simulations, performed in microcomputers, for teaching physics to freshmen engineering students at Faculdade de Engenharia Industrial (FEI). These simulations have been developed using a commercial software and are employed in lectures as a demonstration tool.

\section{Introdução}

Além do uso do computador para aquisição de dados, o uso de programas de simulação tem sido uma das formas mais recorrentes de introdução do computador nas atividades didáticas [1-4]. Com o uso de programas de simulação torna-se viável realizar experimentos que só seriam possíveis de serem feitos em laboratórios muito bem equipados. A utilização destes mundos virtuais, pode também ajudar a esclarecer aspectos, às vezes sutis, de um sistema físico. Aliado a isso, temos o grande interesse demonstrado pelos alunos no manuseio do computador, e que pode ser canalizado para o aprendizado dos mais variados temas. É claro que um software por si só pode não funcionar como um estímulo à aprendizagem. O sucesso irá depender da integração do mesmo ao currículo e às atividades desenvolvidas em sala de aula [5]. No entanto, uma vez realizada de forma consciente, a utilização de simulações no lugar de experimentos reais pode ajudar, e muito, na compreensão de certos fenômenos físicos. Sem se ater a detalhes experimentais, e através da utilização de uma ferramenta que faz parte de seu cotidiano, o aluno pode voltar toda a sua atenção à essência do problema em estudo [6].

O uso de simulações em aulas de laboratório já vem sendo feito em vários projetos pilotos fora do Brasil [79] e também no Brasil [2]. No entanto, a sua utilização como recurso para a realização de demonstração em 
aulas de teoria, criando-se desta forma uma espécie de "laboratório de demonstrações virtuais" é uma forma pouco explorada no Brasil. Além do seu uso direto em sala de aula, a criação de um laboratório de demonstrações virtuais possibilita a disponibilização do material elaborado para as aulas, para acesso posterior pelos alunos. Assim, os alunos podem, a princípio, utilizar estas demonstrações como um complemento dos assuntos tratados em aula, podendo o material ser acessado no instante em que eles estiverem reestudando o tópico abordado pela demonstração simulada. Uma outra vantagem importante, é o baixo custo de instalação e manutenção. Os recursos materiais necessários para a sua utilização em aula restringem-se ao software de simulação, computador e projetor multimídia, os quais podem ser utilizados para a realização de uma enorme gama de demonstrações [10].

\section{O computador no ensino}

No âmbito da educação, Liguori [3] considera como meio de ensino precursor dos computadores, a máquina de ensinar de Skinner, cujo modelo baseava-se nos princípios psicológicos estabelecidos a partir do exame experimental do comportamento no campo do programa do reforço ou condicionamento operante. Skinner propôs um método de aprendizagem por ensino programado usando máquinas de ensinar, no qual o ensino é caracterizado como um programa de recompensas oportunamente administradas. Com o objetivo de modelar a conduta do aluno, a ele são proporcionados estímulos. Se o aluno acerta as respostas, recebe reforços positivos.

A utilização dos computadores como recursos didáticos para o ensino, na linha behaviorista de Skinner, se generaliza com programas denominados de CAI (Computer Assisted Instruction - instrução auxiliada por computador), que tinham o objetivo de levar informações ao usuário por intermédio de um diálogo entre o tutor (computador) e o tutorado (usuário). Existe um modelo de software educativo (geralmente denominado tutorial) em que ainda prevalece esta teoria.

$\mathrm{O}$ uso de computadores no ensino, no entanto, não tem se restringido ao modelo baseado na linha behaviorista de Skinner. Para Valente [4], as novas modalidades de uso do computador na educação apontam para uma nova direção, ou seja, o uso desta tecnologia não como "máquina de ensinar" mas, como uma nova mídia educacional, em que o computador passa a ser uma ferramenta educacional, uma ferramenta de complementação, de aperfeiçoamento e de possível melhora no processo de ensino.

Vivemos, atualmente, num mundo dominado pela informação e por processos que se alteram de maneira muito rápida. Alguns fatos e processos específicos que a escola ensina, rapidamente se tornam obsoletos. Deste modo, ao invés de apenas memorizar informação, os estudantes devem ser ensinados a buscar e a usar a informação para transformá-la em conhecimento. Estas mudanças podem ser introduzidas com o auxílio do computador, que pode propiciar as condições para os estudantes exercitarem a capacidade de procurar e selecionar informações, resolver problemas e aprender de forma independente.

Tem-se utilizado a informática em educação basicamente em duas grandes linhas: para o próprio ensino de informática e computação, e para desenvolver o ensino de diferentes áreas de conhecimento, isto é, como um recurso didático auxiliar [11].

As formas de utilização dos computadores como recurso didático podem ser classificadas nas seguintes modalidades: tutoriais, de exercícios ou prática, demonstrações, simulações e jogos [3, 4]. No entanto, segundo Liguori [3], deve-se notar que esta classificação é arbitrária, uma vez que os limites entre uma ou outra modalidade não são nítidos e um mesmo programa pode combinar várias destas modalidades, as quais, de maneira resumida, poderiam ser assim diferenciadas:

- tutoriais: os programas atuam como "tutores", fornecendo informações e a seguir procurando verificar, por meio de perguntas, se o aluno compreendeu o tópico abordado, constituindo-se numa versão computacional da instrução programada;

- exercícios ou práticas: os programas apresentam problemas de uma determinada área para serem resolvidos pelo aluno, sendo muito usados para revisão de assuntos vistos em classe e que envolvam memorização e repetição;

- demonstrações: que permitem ao aluno visualizar na tela do computador o que ocorre quando se alteram variáveis num determinado processo, permitindo que se possa realizar diferentes observações, em pouco tempo;

- simulações: que permitem reproduzir na tela do computador o comportamento de um dado sistema, a partir do modelo teórico que o descreve;

- jogos: que se constituem numa maneira divertida de aprender. Os jogos de maior valor pedagógico, são os que promovem habilidades cognitivas complexas, como o Tetris, o xadrez, os quebra-cabeças, os jogos de memória, etc. [3]

Uma forma atual de uso dos computadores envolve a sua utilização como ferramenta de pesquisa para obterse os mais variados tipos de informação. Com o advento das redes de computadores, mais especificamente, com a popularização da Internet, passou-se a ter acesso a grandes bases de dados localizadas nos mais diversos pontos do planeta. Com a utilização de um ambiente gráfico, a WWW (World Wide Web), e de recursos de hipermídia, a Internet tem sido considerada uma das formas promissoras de uso do computador no ensino.

Segundo Rosa [2], as formas mais recorrentes de aplicação do computador em ensino de Física, têm sido em laboratório, na simulação de experiências e o uso 
como ferramenta para coleta e/ou análise de dados em tempo real (cálculo de médias e desvios padrão, confecção de gráficos e tabelas, etc.). Em aulas de teoria, o computador tem sido utilizado na forma de instrução assistida por computador, e na forma de simulação de situações físicas.

\section{Uso de simulações em aulas}

Algumas iniciativas têm sido realizadas no sentido de aplicar o computador de forma mais intensiva no ensino de Física na FEI. No primeiro semestre de 1996, foram introduzidas simulações realizadas em microcomputador em aulas de laboratório, cujos softwares foram desenvolvidos na própria Instituição. Este trabalho foi realizado com alunos do segundo período do curso de engenharia, matriculados no curso de Física II [12].

Um dos programas desenvolvidos foi para simular em computador um pêndulo simples animado em tempo real, que permite ao estudante variar parâmetros como o comprimento do fio e aceleração da gravidade. Através da utilização de um cronômetro do próprio programa e controlado pelo aluno, este pode estudar o comportamento do período de oscilação do pêndulo em função dos diferentes parâmetros físicos. O outro experimento simulado foi sobre "oscilações amortecidas", e consiste basicamente de um sistema mola/massa sujeito a um amortecimento causado pela imersão da massa em um meio viscoso. O programa gera para um certo conjunto de dados, os gráficos de posição, velocidade e aceleração da massa oscilante, em função do tempo. As condições de amortecimento subcrítico, crítico e supercrítico podem ser verificadas através da variação dos parâmetros do experimento. O experimento permite ainda que se aplique a utilização de papel monologarítmico para a linearização de gráficos de eventos com comportamento exponencial. A partir dos gráficos obtidos, propõe-se a obtenção do coeficiente de amortecimento, bem como do coeficiente de resistência viscosa do meio.

Em seguida, foram também desenvolvidos softwares para as aulas de laboratório dos alunos do primeiro período (Física I), um deles sobre "balística" e outro sobre "força de atrito de escorregamento". No programa sobre "balística", o estudante pode simular o comportamento de um projétil que é lançado de uma dada altura com a velocidade horizontal não nula, e sujeito a queda livre. É possível observar vários tipos de gráficos como a trajetória descrita pelo projétil e a componente vertical da velocidade como uma função do tempo. As simulações podem ser ajustadas para diferentes valores da força da gravidade, massa e velocidade inicial, e os resultados podem ser comparados. Os alunos, através da linearização de curvas, podem calcular a velocidade inicial de lançamento, simular a experiência em outros planetas e obter a aceleração da gravidade nestes planetas. No programa de simulação sobre "força de atrito de escorregamento", o usuário tem um plano inclinado que pode ser movido para cima e para baixo na tela do computador. O "passo" na variação do ângulo também pode ser controlado, possibilitando a mudança do ângulo em diferentes degraus. Sobre o plano há um bloco em repouso que é mantido em sua posição pela força de atrito. Após atingido um dado ângulo crítico, o bloco começa a escorregar plano abaixo, sendo possível obter o coeficiente de atrito estático através do cálculo da tangente do ângulo indicado. Neste instante, um cronômetro interno é também disparado e o tempo que o bloco leva para atingir o fim do plano inclinado é medido e apresentado na tela do computador. Assim, o coeficiente de atrito dinâmico também pode ser obtido usando esta informação. Um modo alternativo de obter este coeficiente é mover o plano para baixo (após o bloco ter dado início ao seu deslizamento), verificando o ângulo para o qual a velocidade é constante (é possível visualizar o gráfico de velocidade do bloco em função do tempo). A tangente deste ângulo corresponde ao coeficiente de atrito dinâmico. O programa ainda fornece a possibilidade de se obter os coeficientes de atrito entre diversos pares de superfícies [5].

A partir do primeiro semestre de 2000 foi introduzido de forma sistemática, em aulas de teoria, um software de simulação para a realização de demonstrações. Nesta forma de utilização valeu-se do auxílio de um software comercial para a construção das simulações que são apresentadas em aula pelo professor. Cabe observar que fazemos a diferenciação entre aulas de laboratório e aulas de teoria em virtude das características distintas das salas de aula para um ou outro tipo de aula, assim como a forma como a ferramenta computador é utilizada em cada caso.

As demonstrações simuladas dirigidas para as aulas de teoria foram elaboradas utilizando-se o software "Interactive Physics 5.0@ [13], versão já produzida na língua portuguesa. Existem algumas restrições impostas pelo software, como por exemplo o fato das simulações não serem em tempo real e de necessitarmos do programa para executar as simulações criadas. Uma alternativa para superar esta última restrição, é a criação de um vídeo da simulação (no formato AVI), o que, no entanto, retira toda a interatividade, já que não é possível neste caso alterar parâmetros.

Os tópicos abordados com o uso de demonstrações simuladas em computador, nas aulas de teoria, versam sobre mecânica de partícula material, mais especificamente, são tratados os seguintes temas: cinemática escalar e vetorial de partícula material, princípios de dinâmica de partícula material, trabalho e energia [14]. Cada um destes tópicos é tratado inicialmente de forma analítica e então complementado utilizando-se as simulações correspondentes. As demonstrações em computador têm como uma das finalidades, servir como elemento motivador para as aulas. Além de se ilustrar os 
movimentos que estão sendo estudados através do uso de animações, a simulação permite ainda que se desenvolva a conexão entre o movimento de um corpo e a correspondente representação gráfica.

A preocupação em se utilizar recursos que envolvam simultaneamente a apresentação do fenômeno juntamente com a sua representação gráfica, vem da observação da dificuldade que alguns alunos possuem na interpretação gráfica de problemas de Física. Isto também tem sido observado por outros pesquisadores [15], e entre as dificuldades apontadas, estão a falta do entendimento claro do significado dos gráficos de posição, velocidade e aceleração em função do tempo, bem como a falta de habilidade para interpretar corretamente o significado dos coeficientes angulares e das áreas sob os diversos gráficos. $\mathrm{O}$ uso conjunto de simulações e desenvolvimento teórico de um dado tópico, pode, em princípio, melhorar o entendimento dos alunos nestas situações, pois permite que se visualize o movimento simultaneamente à construção do gráfico.

Nas aulas de teoria, em que a quantidade de alunos é maior do que no laboratório, as intervenções ilustrativas com o emprego de simulações são realizadas pelo próprio professor, com o uso de computador conjugado com projetor multimídia. Pode-se com estas demonstrações, repetir várias vezes o experimento, com modificação de vários parâmetros, buscando auxiliar o aluno na visualização dos movimentos discutidos.

\section{Formas de uso das si- mulações}

Foram experimentadas três formas básicas de uso de simulações em aulas de teoria antes da sua aplicação de forma sistemática no curso de Física I. A primeira envolveu a reserva de uma aula completa (100 minutos) para a realização das demonstrações. Neste tipo de aplicação, observamos que no decorrer da aula, após um período inicial de grande interesse, havia uma diminuição no interesse de parte da turma. Talvez isto acontecesse devido ao uso de luz menos intensa para a realização da projeção, o que acreditamos acabava por cansar o aluno. Na segunda forma de utilização, realizamos as demonstrações diluídas em diversas aulas, utilizando-se apenas uma pequena parte do tempo da aula (cerca de 20 a 30 minutos). Os tópicos tratados neste caso, eram aqueles que viriam a ser estudados, nas aulas seguintes, de forma convencional. A terceira forma, que foi a que se mostrou mais proveitosa, envolveu o uso das demonstrações de modo semelhante ao caso anterior, porém realizadas após ter sido feita a discussão teórica do assunto. Neste caso observou-se que os alunos encontravam-se mais aptos a discutirem os resultados apresentados pelas simulações. Esta foi a forma utilizada quando esta ferramenta foi introduzida de forma sistemática no curso de Física I, a partir do $2^{\circ}$ semestre de 2000 .

Todas as simulações foram desenvolvidas de modo a evitar-se uma sobrecarga informativa nos estudantes. Assim, medidores, botões para mudanças de parâmetros, gráficos, etc., são incluídos somente se forem realmente importantes naquele momento para a discussão proposta. Procurou-se simplificar as simulações para se obter melhor aproveitamento da discussão. Os tópicos tratados nas diversas simulações são aqueles correspondentes ao programa de Física I, ou seja, cinemática e princípios de dinâmica de partícula material, e energia. Estas simulações são primeiramente discutidas de forma conceitual, para então serem analisadas numericamente. O número de simulações a serem mostradas pode variar de turma para turma, dependendo das observações que o professor venha a fazer, no transcorrer da demonstração. Normalmente, pelo questionamento dos alunos no que se refere aos resultados que se espera obter com as simulações programadas, é possível ter-se uma idéia do grau de dificuldade dos tópicos abordados. Com isto, procura-se evitar a apresentação das simulações que possam ser simples demais para determinada classe, o que poderia vir a diminuir o interesse da turma no uso da ferramenta.

\section{Descrição de algumas si- mulações utilizadas em aulas de teoria}

\section{V.1. Movimento unidimensional na hori- zontal}

No tópico sobre "Movimento em uma dimensão", as simulações têm sido utilizadas para estudar movimento uniforme, movimento uniformemente variado e movimentos mais complexos, procurando-se explorar os conceitos de velocidade média e instantânea, aceleração média e instantânea. Discute-se também os conceitos de derivação e integração matemática e os correspondentes significados geométricos. Os diversos parâmetros descritivos dos movimentos estudados são alterados durante a demonstração. Pode-se pedir aos alunos que realizem determinados cálculos, utilizandose os conceitos teóricos anteriormente discutidos, para que os resultados destes cálculos sejam comparados com os que são obtidos pela simulação. Os diversos gráficos também são apresentados para melhor visualização dos fenômenos. 


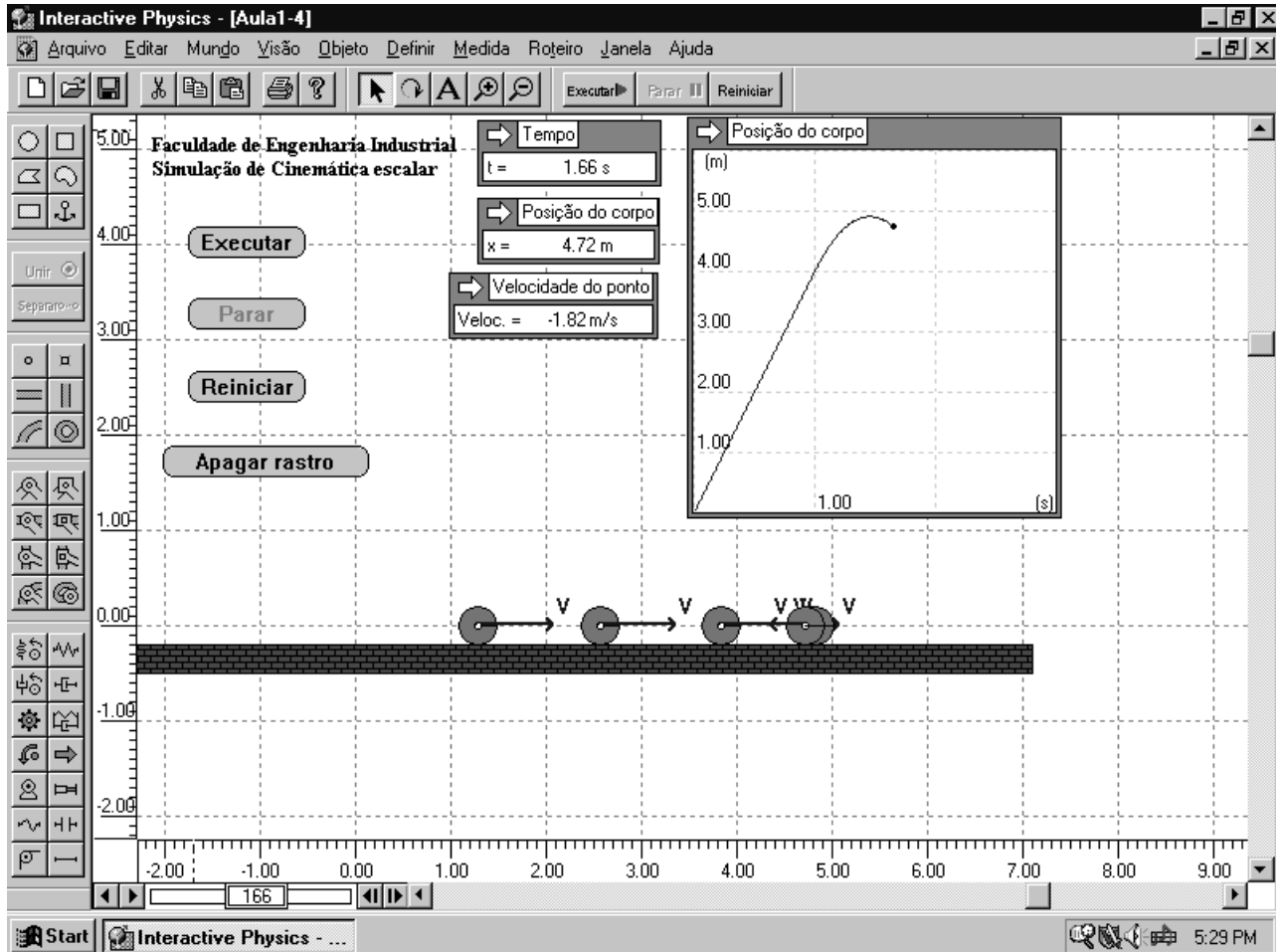

Figura 1. Simulação de movimento em uma dimensão (partícula movimentando-se em um piso horizontal) e a respectiva representação gráfica da posição em função do tempo.

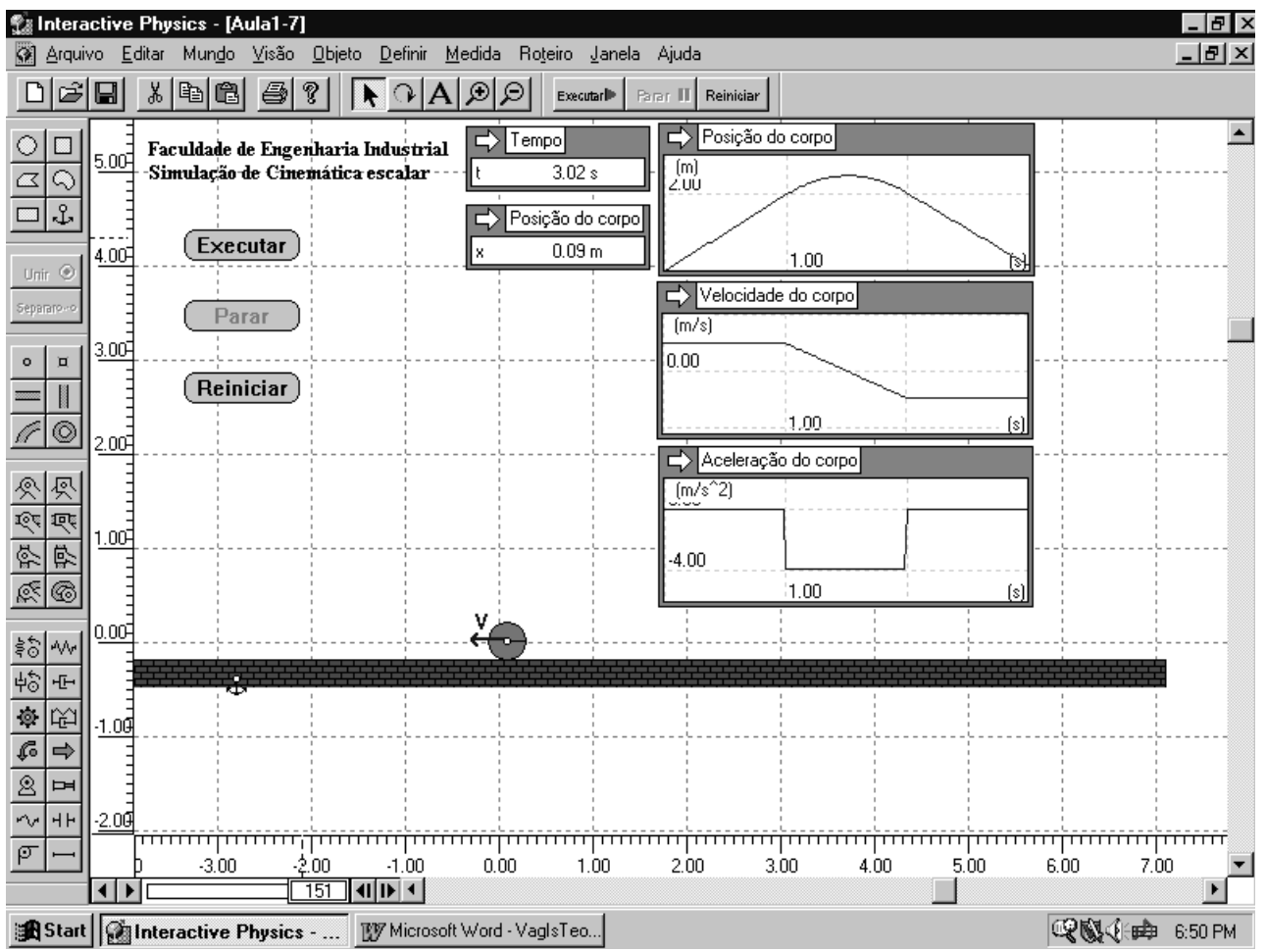

Figura 2. Simulação do movimento de um corpo sobre um piso horizontal e as representações gráficas da posição, da velocidade e da aceleração em função do tempo.

Na simulação mostrada na figura 1 , ao se clicar no botão "Executar", o corpo inicia seu movimento sobre um piso horizontal, para a direita. Pela observação direta do movimento da partícula, é fácil perceber que, no início, o movimento é uniforme, acompanhando-se para tanto os instantes de tempo e as respectivas velocidades. Concomitante ao movimento do corpo sobre o piso horizontal, pode-se acompanhar a construção do 
gráfico "posição do corpo versus tempo", linear até o instante $\mathrm{t}=1 \mathrm{~s}$. Depois do instante $\mathrm{t}=1 \mathrm{~s}$, o gráfico deixa de ser linear. O ponto máximo do gráfico ocorre quando, no piso horizontal a posição do corpo atinge o valor máximo. Nesse momento pode-se ler o valor zero da velocidade do corpo. Logo após, no piso horizontal, o corpo move-se para a esquerda, a velocidade passa a ser negativa, e no gráfico a posição do corpo passa a diminuir. Depois de um certo instante, o movimento volta a ser uniforme, no sentido negativo. Podemos efetuar cálculos da velocidade média, velocidade instantânea, explorar os conceitos de derivação e mostrar que o coeficiente angular da reta tangente ao gráfico, em cada instante, corresponde à velocidade instantânea do corpo. Outro ponto importante é mostrar ao aluno a distinção entre o movimento do corpo, que ocorre no piso horizontal, e o gráfico descrito, que é a representação da variação da posição do corpo no decorrer do tempo. Neste caso, é fácil perceber que, embora a trajetória seja uma linha reta, o gráfico de posição versus tempo não é uma reta. Também a diferenciação entre os conceitos de deslocamento escalar e de espaço percorrido podem ser melhor esclarecidos com a simulação, assim como os de movimento acelerado e retardado.

Na simulação mostrada na figura 2, o corpo se move sobre o piso horizontal, e neste caso há medidores de tempo e posição do corpo, além dos gráficos temporais da posição, velocidade e aceleração. Pode-se verificar que, nos intervalos de tempo em que a posição varia linearmente com o tempo, a velocidade é constante, o gráfico respectivo é paralelo ao eixo dos tempos e a aceleração é zero. Quando a posição cresce mais lentamente, a velocidade diminui. No momento em que a posição é máxima, a velocidade é nula. Quando a posição passa a diminuir, a velocidade vai se tornando mais negativa. Observa-se também, pelo gráfico da aceleração, que esta é negativa desde que a velocidade passou a diminuir. A partir do momento em que a posição do corpo passa a diminuir de maneira constante, a velocidade volta a ser paralela ao eixo dos tempos, e a aceleração volta a zero.

\section{V.2. Movimento em duas dimensões}

No tópico "Movimento em duas dimensões", temos aplicado simulações que ilustram o caráter vetorial dos movimentos. Os problemas de lançamento de projéteis podem ser melhor entendidos com as simulações que permitem visualizar o porquê da decomposição deste tipo de movimento em eixos cartesianos. Assim, na simulação da figura 3, pode-se verificar que:

- em cada instante, a velocidade vetorial $v$ é tangente à trajetória;

- em qualquer instante, a componente horizontal da velocidade $\left(v_{x}\right)$ é constante;

- a componente vertical da velocidade $\left(v_{y}\right)$ decresce na subida, torna-se zero no ponto mais alto da trajetória, passando então a crescer negativamente;

- as coordenadas do projétil, em qualquer instante, correspondem exatamente à abscissa da projeção horizontal do projétil e à ordenada da projeção vertical do mesmo, mostrando que, de fato, o movimento do projétil na trajetória parabólica pode ser decomposto num movimento uniforme, na horizontal, e num movimento uniformemente variado na vertical;

- no quadro indicativo da "velocidade do corpo", pode-se verificar a constância da projeção horizontal da velocidade, a variação da projeção vertical da velocidade, assim como o módulo da velocidade do projétil em qualquer instante;

- o módulo da velocidade do projétil no momento do impacto é igual ao módulo da velocidade de lançamento do mesmo;

Na simulação mostrada na figura 4, ainda sobre movimento de projéteis, pode-se analisar:

- a altura atingida pelo projétil e o alcance horizontal em função da velocidade inicial e do ângulo de lançamento;

- para uma determinada velocidade inicial de lançamento, qual o ângulo em que ocorre o máximo alcance horizontal;

- para uma determinada velocidade inicial de lançamento, que um mesmo alcance horizontal é obtido para dois ângulos complementares entre si.

A simulação seguinte também está incluída no tópico "Movimento em duas dimensões". Na simulação mostrada na figura 5, pode-se estudar, por exemplo:

a) movimento circular uniforme, num plano horizontal

- velocidade vetorial, sempre tangente à trajetória;

- a aceleração total é a própria aceleração centrípeta.

b) movimento circular num plano vertical

- a aceleração vetorial resultante não aponta, em geral, para o centro da circunferência; ela pode ser decomposta nas componentes tangencial e normal;

- para um determinado ângulo, pode-se calcular os módulos das acelerações tangencial, normal e resultante; o valor da aceleração resultante, obtida por cálculo, pode ser comparado com o valor indicado na tela;

- com a partícula em movimento, pode-se "cortar a corda", verificando que a partícula, a partir desse instante, passa a executar movimento de lançamento;

- diminuindo o valor da velocidade inicial, o movimento descrito pode passar a ser o de um pêndulo simples. 


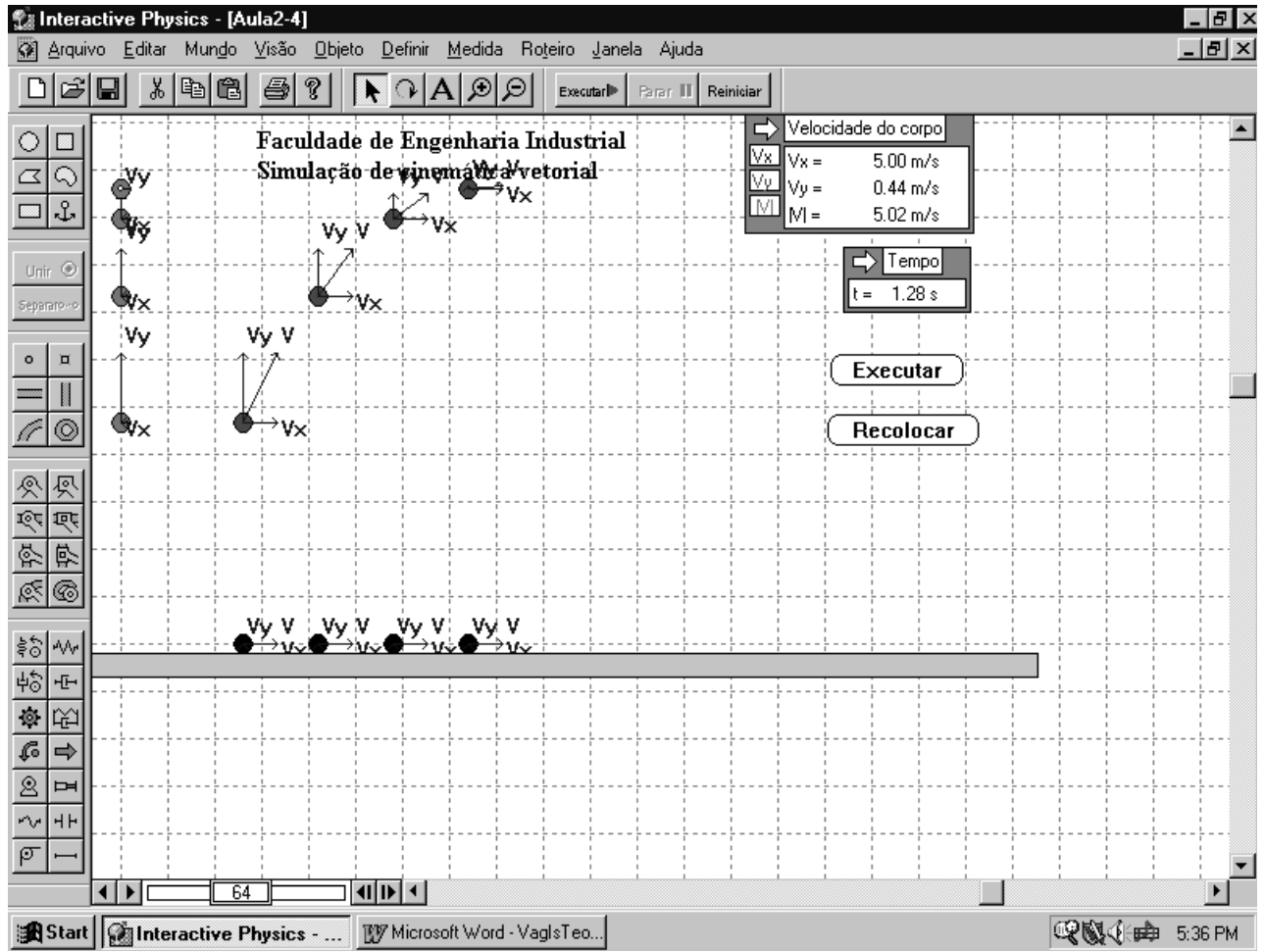

Figura 3. Simulação utilizada para discutir movimento em duas dimensões, análise da velocidade vetorial e decomposição do movimento em eixos cartesianos.

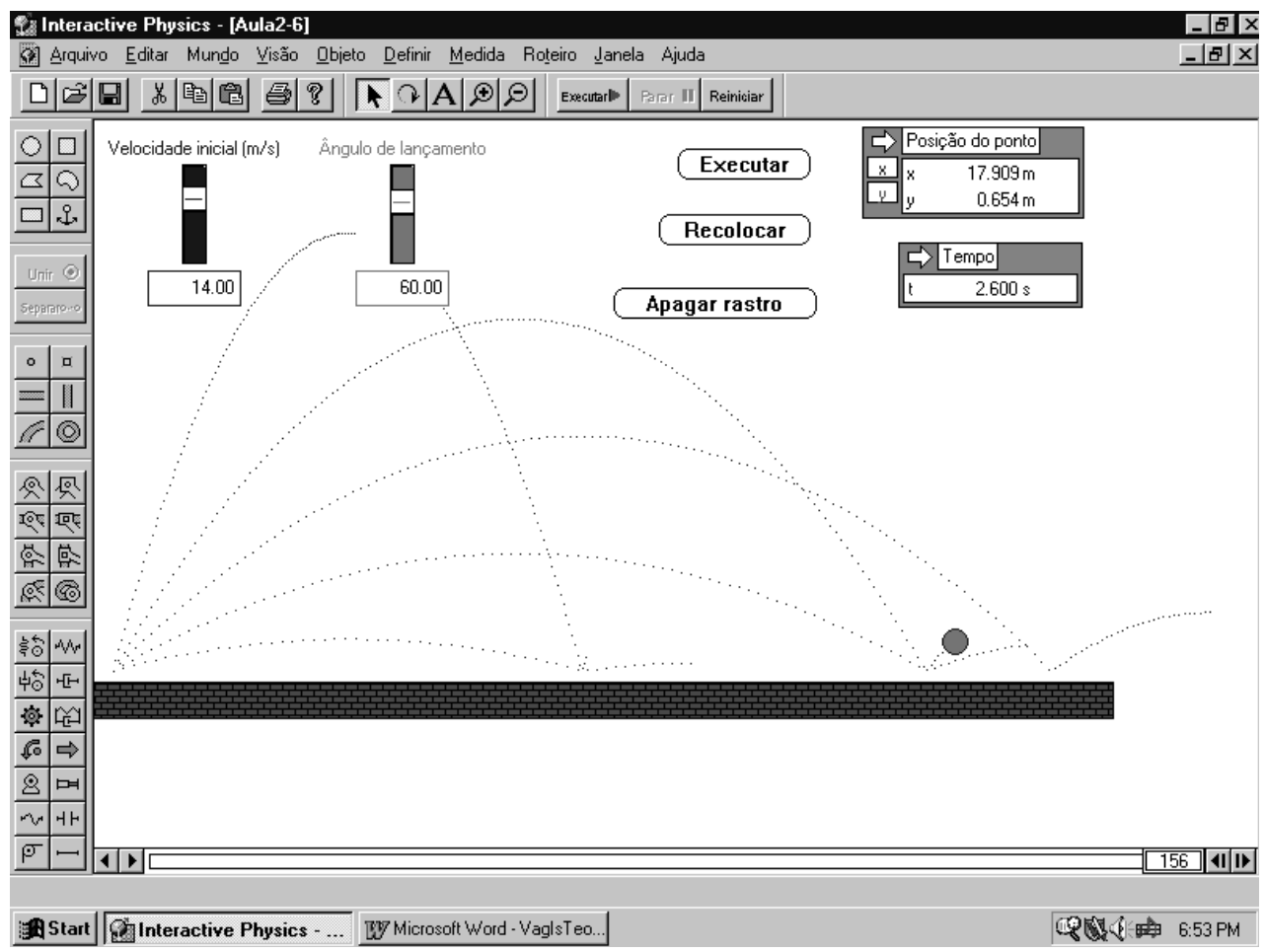

Figura 4. Simulação de lançamento de projétil com velocidade inicial e ângulo de lançamento ajustáveis. 


\section{V.3. Leis do movimento}

No tópico sobre "Leis do movimento", diversas situações são simuladas para ilustrar os importantes conceitos de resultante das forças, inércia, ação e reação. As simulações têm sido úteis também para o estudo das forças de atrito, movimentos em planos inclinados e na análise da dinâmica de movimentos em que são utilizadas polias ou roldanas.

Durante a discussão deste tópico, uma das simulações utilizadas é aquela mostrada na figura 6 , na qual:

- a força externa aplicada sobre o bloco pode ser ajustada em módulo e em direção;

- a velocidade inicial pode ser ajustada, podendo o bloco estar inicialmente parado ou caminhando para a direita ou para a esquerda, no piso horizontal;

- os mostradores indicam os valores da aceleração, força peso (FG), força de atrito (FF), força normal do piso sobre o bloco (FN);

- os coeficientes de atrito estático e dinâmico são conhecidos, para que se possa fazer uma análise quantitativa do problema;

- com o bloco inicialmente parado e aplicando-se a força externa horizontalmente, pode-se verificar a proporcionalidade entre a força de atrito e a força externa aplicada, até a iminência de escorregamento;

- quando se aplica a força externa obliquamente, fica claro que a força normal $\mathrm{FN}$ não tem valor igual ao da força peso FG, confusão freqüente para vários estudantes;

- diversas outras situações podem ser simuladas com a modificação dos parâmetros, e vários conceitos físicos podem ser melhor esclarecidos, como por exemplo a necessidade de aplicação de uma força mínima para se iniciar o movimento, e a diminuição da força de atrito após o início do movimento.

\section{Observações sobre o uso das simulações}

Como já dissemos, temos utilizado simulações de experiências em atividades de laboratório de Física, e como ferramenta de demonstração para o professor introduzir, ilustrar ou discutir um determinado conceito físico, em aulas de teoria. O intuito de tais demonstrações é o de possibilitar uma melhor visualização dos sistemas físicos estudados. Uma das observações mais claras que se faz quando se utiliza demonstrações baseadas em simulações em computador, é que os alunos, de maneira geral, se tornam mais participativos. A possibilidade de rapidamente mudar parâmetros, e verificar a conseqüência nos movimentos estudados, incita os estudantes a querer conhecer o comportamento dos sistemas físicos nas mais diversas situações. Este tipo de aula, mais interativa, é um dos elementos que pode tor- nar o processo de ensino mais eficiente, embora tenha sido verificado que não é suficiente [16].

Algumas observações qualitativas em termos de desempenho dos alunos em provas, mostram que, embora em certas situações eles continuem tendo dificuldades na manipulação das funções que descrevem o movimento de um corpo, o entendimento conceitual de determinados aspectos, como a interpretação gráfica do movimento, parece ter sido melhorada. Isto é, nos pontos que foram reforçados através do uso de demonstrações feitas com auxílio de programas de simulação, o desempenho foi melhor do que naqueles em que este recurso não foi utilizado. É importante, no entanto, ter em mente que a melhora no desempenho pode ter sido causada pelo fato de se ter insistido em determinados pontos, o que poderia, em princípio, ser também obtido utilizando-se qualquer outro método. O sucesso do estudante pode não estar necessariamente ligado à simulação utilizada [9].

Em determinadas situações, tem sido reportada a ausência de uma melhora significativa na performance dos alunos quando é utilizada alguma forma de nova metodologia de ensino [17]. Particularmente, sobre o uso de simulações em computador, há estudos onde foi observada melhora na performance dos alunos [18, $19,20]$ e situações onde a diferença no desempenho dos alunos que utilizaram um método tradicional de ensino e um utilizando simulações em computador foi extremamente pequena [9]. Existem também posições contrárias à facilitação excessiva da visualização dos fenômenos físicos, pois acredita-se que possam diminuir a possibilidade do aluno refletir sobre o assunto, causando assim uma limitação de suas habilidades de abstração [21].

Não se deve também esquecer das particularidades apresentadas pelos alunos. Sem dúvida, a grande maioria dos estudantes já vem acostumada a lidar com a informática e a multimídia. O computador é uma ferramenta que já faz parte de seus cotidianos. Porém, há aqueles que sentem dificuldades ao lidar com os computadores e aqueles que não sentem nenhum atrativo pelas máquinas. Há também o problema de que certas simulações de experiências não exercem muita atração pela sua própria característica, que deve procurar ser didática e exploratória, ou pela falta da animação sofisticada que os alunos estão acostumados a observar nos jogos ou simulações de outra natureza.

Temos buscado atualmente levantar o real grau de interesse demonstrado pelos estudantes no uso deste tipo de ferramenta, através da aplicação de um questionário. No questionário aplicado a 270 alunos de Física I no primeiro semestre de 2000 sobre o uso de simulações nas aulas de teoria, $42 \%$ responderam que estas simulações auxiliaram bastante, $52 \%$ que as mesmas auxiliaram razoavelmente e $3 \%$ que elas não auxiliaram no entendimento do assunto. Quanto à freqüência de emprego de simulações demonstrativas nas aulas de 


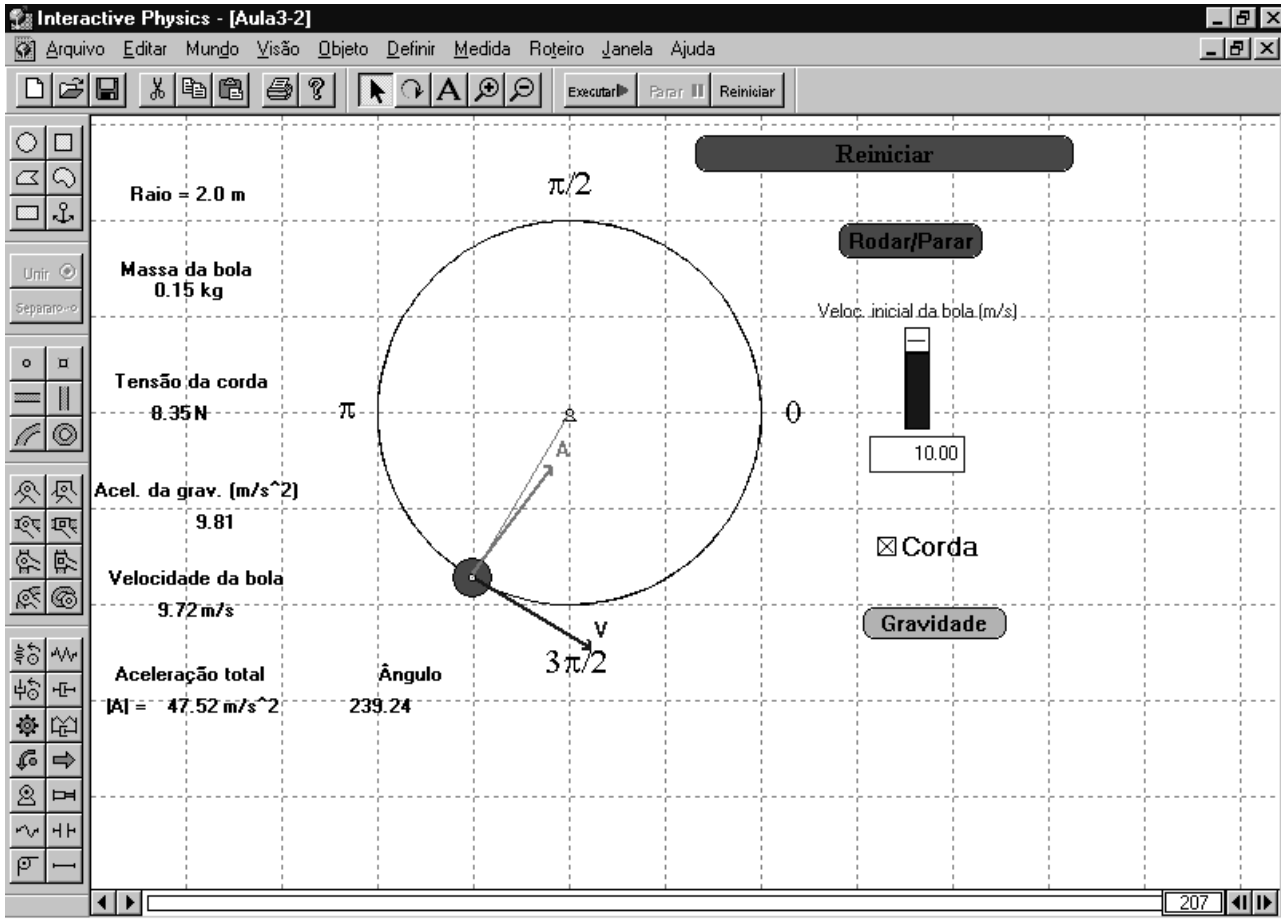

Start ginteractive Physics - ... Wh Microsoft Word-Vagls Teo...

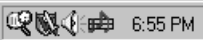

Figura 5. Simulação de movimento circular num plano horizontal ou vertical.

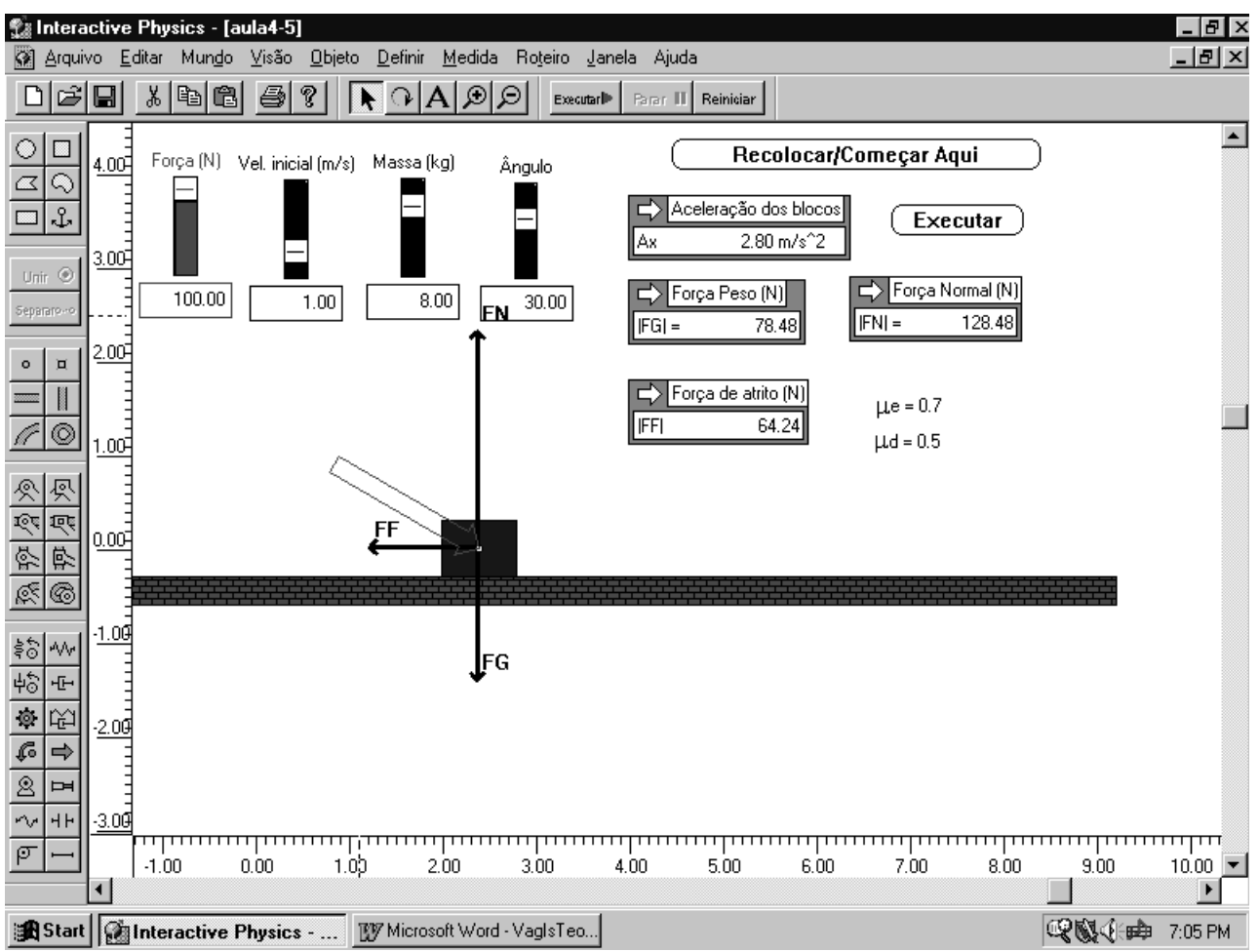

Figura 6. Simulação de um bloco sujeito a uma força externa, na qual se pode explorar as leis do movimento. 
teoria, $59 \%$ responderam que elas deveriam ocorrer "na maior parte das vezes", $38 \%$ "algumas vezes" e $3 \%$ "nunca". Pediu-se ainda que os alunos informassem se preferiam as aulas de teoria com simulação ou sem simulação e as respostas foram que $34 \%$ preferem as aulas sem simulação, $41 \%$ preferem aulas com simulação e $24 \%$ "tanto faz". Quanto às simulações das experiências nas aulas de laboratório, $53 \%$ foram de opinião de que elas "auxiliaram bastante" no entendimento do assunto, $42 \%$ de que elas "auxiliaram razoavelmente" e $2 \%$ de que elas "não trouxeram contribuição". Comparandose as aulas de laboratório real (em que os alunos trabalham em grupos de até 3) com as aulas de simulação em que cada aluno utiliza um microcomputador, $27 \%$ responderam preferir as aulas no laboratório real, $48 \%$ as aulas de simulações e para $24 \%$, "tanto faz".

Em uma segunda etapa, procuraremos verificar o grau de melhora conceitual, através da aplicação de testes padrão abordando os diversos tópicos tratados pela disciplina. Neste aspecto, testes já bastante explorados fora do Brasil, como o "Force Concept Inventory" [22] ou o "Mechanics Baseline Test" [23], adaptados para as características de nossos cursos serão de grande valia. A aplicação preliminar de uma versão do "Mechanics Baseline Test" já foi realizada no $2^{\text {Q }}$ semestre de 1999 e no $2^{Q}$ semestre de 2000 , com o intuito de se verificar as dificuldades conceituais dos alunos ingressantes. No entanto, para o levantamento do ganho conceitual obtido com a aplicação de recursos de simulação em sala de aula, será importante aplicar um pré-teste (antes do aluno ter cursado a disciplina) e um pós-teste (após o aluno ter cursado a disciplina) nas duas situações, isto é, sem o uso das demonstrações simuladas em computador e com o seu uso. Além disso, uma vez que o curso é semestral e que a disputa no vestibular realizado no meio do ano é menor do que aquela realizada no início do ano, para a obtenção de resultados confiáveis seria importante realizar a aplicação deste instrumento com os dois tipos de turmas (aquelas que entram no início do ano e aquelas que entram no meio do ano). Pretende-se realizar este trabalho, porém acreditamos que o levantamento dos dados deverá levar pelo menos 2 anos.

Mesmo não tendo sido aplicado até o momento nenhum instrumento objetivo que confirme ou não um melhor desempenho dos alunos quando se utiliza o computador como ferramenta didática, acreditamos que o seu uso não possa ser ignorado. Primeiramente, porque, como podemos observar através dos dados discutidos anteriormente, a grande maioria dos alunos prefere que este tipo de ferramenta seja utilizada, e acha que esta os auxilia na compreensão dos vários tópicos abordados pela disciplina. Em segundo lugar, porque os computadores apresentam um papel fundamental para os profissionais de engenharia, e deste modo é importante que os estudantes pelo menos conheçam as potencialidades oferecidas por estas máquinas. A possibilidade de se criar um modelo, fazer previsões baseadas neste modelo, obter resultados através de uma simulação e comparar este resultados com as previsões feitas, é apenas um dos aspectos importantes desta ferramenta. A exploração de novos domínios, não acessíveis no laboratório convencional, também tem seu papel de destaque, e podem sugerir novas aplicações para os conhecimentos adquiridos pelos estudantes.

A melhora no processo do uso deste tipo de recurso só será possível com o conhecimento e o aperfeiçoamento constante dos profissionais envolvidos com a área de ensino. Sem a experiência e o conhecimento do que é possível fazer através do uso do computador, muito pouco pode ser melhorado em relação ao ensino baseado na pura transmissão de informações.

\section{Conclusões}

Em face das observações que temos realizado, acreditamos que os resultados do uso de simulações em computador em aulas de teoria têm sido satisfatórios, principalmente em termos de uma maior motivação dos alunos. Estas observações refletem as impressões qualitativas obtidas pelos professores da disciplina, bem como aquelas levantadas pelas respostas dos alunos ao questionário. Uma verificação objetiva da melhora na aquisição e fixação de conceitos deverá ser realizada numa próxima etapa, através do uso de testes conceituais similares ao "Force Concept Inventory" e ao "Mechanics Baseline Test".

\section{Agradecimentos}

Os autores agradecem ao Prof. Augusto M. dos Santos, pelos valiosos comentários no desenvolvimento das simulações, e por adotar a idéia do uso de simulações no curso de Física I, disciplina da qual é o coordenador nesta Instituição de Ensino.

\section{References}

[1] R.M.E. Sabbatini, Tecn. Educ. 12, 21 (1983).

[2] P.R.S. Rosa, Rev. Bras. Ens. Fís. 17, 182 (1995).

[3] Laura M. Liguori, As novas tecnologias da informação e da comunicação no campo dos velhos problemas e desafios educacionais. In: Edith Litwin (org.). Tecnologia educacional: política, histórias e propostas. Ed. Artes Médicas, Porto Alegre, 78-97 (1997).

[4] J.A. Valente, Diferentes usos do computador. http://www.proinfo.gov.br. Em 03/08/1999.

[5] V.B. Barbeta, Use of simulation software for physics teaching. Anais do International Conference on Engineering Education (ICEE), Rio de Janeiro, (1998).

[6] R.K. Thornton, Phys. Educ. 22, 231 (1987).

[7] L. Borghi, A. De Ambrosis, P. Mascheretti e C.I. Massara, Phys. Educ. 22, 117 (1987). 
[8] P. Martínez-Jiménez, E. Casado, J.M. MartínezJiménez, M. Cuevas-Rubiño, D. González- Caballero e F. Zafra-López, Comput. in Phys. 11(1), 31 (1997).

[9] R.N. Steinberg, Phys. Educ. Res., Am. J. Phys. Suppl. 68(7), S37 (2000).

[10] V.B. Barbeta, Recursos de simulação em computador em aulas de física para engenharia. XXVIII Congresso Brasileiro de Ensino de Engenharia - COBENGE, (2000).

[11] M.E.B.T.M.P. Almeida, Informática e educaçẫo - diretrizes para uma formação reflexiva de professores. Dissertação de Mestrado em Educação, Supervisão e Currículo. São Paulo, Pontifícia Universidade Católica de São Paulo, (1996).

[12] V.B. Barbeta e J.M. Bechara, Uso de simulações em computador em aulas de laboratório de física. Anais do XXIV Congresso Brasileiro de Ensino de Engenharia COBENGE, 505- 516 (1996).

[13] O software Interactive Physics foi desenvolvido pela empresa americana MSC (antiga Knowledge Revolution) e ela pode ser acessada, para obtenção de demonstrativo do software, no endereço http://www.krev.com.
[14] As simulações desenvolvidas com o Interactive Physics e os tópicos abordados podem ser obtidos no endereço http://www.fei.br/fisica/demo_int.zip

[15] R.J. Beichner, Am. J. Phys. 62, 750 (1994).

[16] K. Cummings, J. Marx, R. Thornton e D. Kuhl, Phys. Educ. Res., Am. J. Phys. Suppl 67 (7), S38 (1999).

[17] J. Mottmann, The Phys. Teacher, 37, 74 (1999).

[18] R. Beichner, L. Bernold, E. Burniston, P. Dail, R. Felder, J. Gastineau, M. Gjersten e J. Risley, Am. J. Phys. 67, S16 (1999).

[19] B.S. Eylon, M. Ronen e U. Ganiel, J. Sci. Educ.Technol. 5 (2), 93 (1996).

[20] D.J. Grayson e L.C. McDermott, Am. J. Phys. 64, 557 (1996).

[21] J.J. Carr, Am. J. Phys. 68 (11), 977 (2000).

[22] D. Hestenes, M. Wells e G. Swackhamer, The Phys. Teacher, 30, 141 (1992).

[23] D. Hestenes e M. Wells, The Phys. Teacher, 30, 159 (1992). 